\title{
Screen or not to screen for peripheral arterial disease: guidance from a decision model
}

\author{
Anil Vaidya ${ }^{1,2^{*}}$, Manuela A Joore ${ }^{1,2}$, Arina J ten Cate-Hoek ${ }^{3}$, Hugo ten Cate $^{3}$ and Johan L Severens ${ }^{4}$
}

\begin{abstract}
Background: Asymptomatic Peripheral Arterial Disease (PAD) is associated with greater risk of acute cardiovascular events. This study aims to determine the cost-effectiveness of one time only PAD screening using Ankle Brachial Index (ABI) test and subsequent anti platelet preventive treatment (low dose aspirin or clopidogrel) in individuals at high risk for acute cardiovascular events compared to no screening and no treatment using decision analytic modelling.

Methods: A probabilistic Markov model was developed to evaluate the life time cost-effectiveness of the strategy of selective PAD screening and consequent preventive treatment compared to no screening and no preventive treatment. The analysis was conducted from the Dutch societal perspective and to address decision uncertainty, probabilistic sensitivity analysis was performed. Results were based on average values of 1000 Monte Carlo simulations and using discount rates of $1.5 \%$ and $4 \%$ for effects and costs respectively. One way sensitivity analyses were performed to identify the two most influential model parameters affecting model outputs. Then, a two way sensitivity analysis was conducted for combinations of values tested for these two most influential parameters.
\end{abstract}

Results: For the PAD screening strategy, life years and quality adjusted life years gained were 21.79 and 15.66 respectively at a lifetime cost of 26,548 Euros. Compared to no screening and treatment (20.69 life years, 15.58 Quality Adjusted Life Years, 28,052 Euros), these results indicate that PAD screening and treatment is a dominant strategy. The cost effectiveness acceptability curves show $88 \%$ probability of PAD screening being cost effective at the Willingness To Pay (WTP) threshold of 40000 Euros. In a scenario analysis using clopidogrel as an alternative anti-platelet drug, PAD screening strategy remained dominant.

Conclusion: This decision analysis suggests that targeted $A B \mid$ screening and consequent secondary prevention of cardiovascular events using low dose aspirin or clopidogrel in the identified patients is a cost-effective strategy. Implementation of targeted PAD screening and subsequent treatment in primary care practices and in public health programs is likely to improve the societal health and to save health care costs by reducing catastrophic cardiovascular events.

Keywords: Cost-effectiveness, Peripheral arterial disease, Ankle brachial index, Decision model

\section{Background}

Peripheral Arterial Disease (PAD) is a common disorder with a prevalence estimated at $16 \%$ in those aged over 55 years and $29 \%$ in high-risk groups [1,2]. PAD is a sign of widespread atherosclerosis also affecting coronary, cerebral and renal arteries. PAD is associated with a

\footnotetext{
* Correspondence: a.vaidya@maastrichtuniversity.nl

'Department of Clinical Epidemiology and Medical Technology Assessment (KEMTA), Maastricht University Medical Centre, Maastricht, The Netherlands ${ }^{2}$ School for Public Health and Primary Care (CAPHRI), Maastricht University, Maastricht, The Netherlands

Full list of author information is available at the end of the article
}

significant reduction in Quality of Life (QoL) and greater risk of acute cardiovascular events [3,4]. The increased risk for cardiovascular morbidity, such as myocardial infarction and stroke, and increased risk for mortality is also observed in asymptomatic patients [5]. The Cardiovascular consequences of $\mathrm{PAD}$, are known to be expensive and contribute substantially to national health care costs [6].

European Society of Cardiology (ESC), American Heart Association (AHA) and American College of Cardiology (ACC) clinical practice guidelines recommend low dose 
aspirin to reduce the cardiovascular events and mortality in symptomatic PAD patients $[7,8]$. Clopidogrel is recommended as an effective alternative anti-platelet therapy to aspirin for secondary prevention in PAD [8]. Ankle Brachial Index (ABI) is used for detection of PAD. The ABI is calculated by measuring both arm and leg blood pressure (at ankle level). This reliable and inexpensive test is highly sensitive and specific for PAD. However, $\mathrm{ABI}$ screening in asymptomatic patients is a controversial topic among the health professionals. United States preventive services task force (USPSTF) assigned a "D" recommendation to the routine screening of PAD [9]. This recommendation is intensely debated and a routine targeted screening for PAD is recommended to increase the frequency of diagnosis, improve the use of recommended medical therapies, and consequently reduce cardiovascular morbidity and mortality rates [10]. Researchers have voiced that 'it's not just about legs' and ABI measurement in asymptomatic individuals should be regarded as the biomarker of cardiovascular disease risk [11]. While expansion of the evidence base for PAD screening is recommended in the year 2011 focussed update of the guidelines [12], targeted ABI screening is recommended by all professional vascular societies including the ACC [8].

The Rotterdam study has identified risk factors that are most strongly associated with PAD such as older age, cigarette smoking, diabetes mellitus, hypercholesterolemia and hypertension [13]. These risk factors can be used to guide targeted ABI screening in a general population over 55 years of age.

In current health care practice, asymptomatic PAD often remains undiagnosed and opportunities for secondary prevention are missed [2]. Therefore, there is a clinical need of early detection of asymptomatic PAD and for the initiation the appropriate preventive treatment in a high risk population. Although, prevention and subsequent treatment comes at a certain cost the secondary prevention of cardio-vascular consequences in PAD patients may at the same time improve prognosis and save healthcare resources. This study aims to determine the cost-effectiveness of PAD screening using ABI and subsequent preventive treatment in high risk individuals at high risk for acute cardiovascular events with low dose aspirin or clopidogrel compared to no screening and treatment.

\section{Methods}

A model-based economic evaluation of targeted ABI screening in high-risk group was performed taking lifetime costs and health effects in account for a Dutch health care setting. Microsoft Excel $2010^{\odot}$ software was used for this modelling work.
Future costs and outcomes were discounted at the rates of $4 \%$ and $1.5 \%$ respectively, as per the Dutch guidelines for pharmaco-economic research [14]. This study was conducted from the societal perspective and indirect costs (productivity loss) were taken into account.

\section{Model approach}

The hypothetical population consists of asymptomatic males and females aged 55 years with at least one of the vascular risk factors identified in the Rotterdam study [13].

The intervention is one time screening in a high risk population at the age of 55 years using $\mathrm{ABI}$, the current standard test to detect PAD in primary care. Screening in principle is intended to take place in the general practitioner's office, in a similar manner as 'The prevention visit' for the cardiovascular risk assessment, defined in the Dutch College of General Practitioners' practice guideline [15]. We modelled that all ABI test positive patients will receive preventive treatment with low dose aspirin in the base case analysis. In a scenario analysis low dose aspirin is replaced with clopidogrel as preventive treatment in patients with a positive test.

ABI screening is compared to no screening of the high risk population and preventive treatment is only given to the incidentally diagnosed or incidentally symptomatic patients. Model Outcomes were life years (LYs), quality adjusted life years (QALYs) and costs. The model has a time horizon of a life time as the hypothetical patient cohort was followed until death. The model cycle duration was one year.

\section{Model structure}

Based on a systematic review of modelling approaches for PAD, we used a combination of two modelling approaches: a decision tree and a Markov state transition model shown in the Figure 1 and Figure 2 [16]. The decision tree was used to determine the number of screened individuals falling into the categories of test positive or test negative on the basis of test accuracy and prevalence of PAD. A Markov model was subsequently used to model the on-going risk of cardiovascular events over a lifetime.

The model assumes that the patient is always in one of a finite number of states of health referred to as Markov states. The time horizon of the analysis is divided into equal increments of time, referred to as Markov cycles, in this case one year. During each cycle, the cohort of patients is redistributed over the Markov states, thus theoretically a patient may make a transition from one state to another. Each state is assigned a utility and a cost. Total costs and utility for screening versus noscreening are calculated depending upon the distribution of the cohort over the Markov states and the length of time spent in each state [17]. 

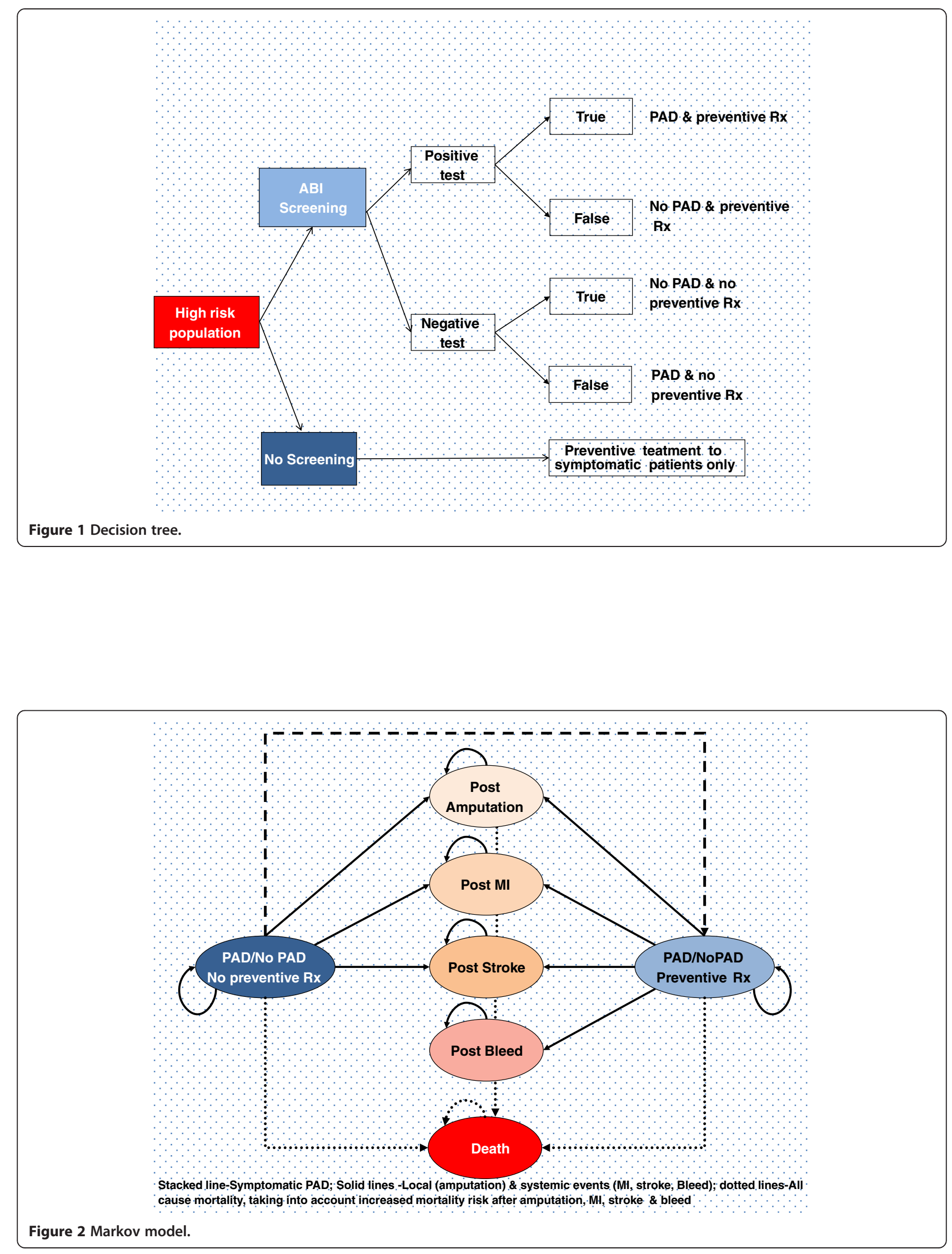
We included all the relevant cardiovascular health states in the Markov model (no PAD, asymptomatic PAD, and symptomatic PAD, post amputation, post myocardial infarction, post stroke, post bleed-in treated patients and the absorbing state of death). Risk reductions of cardiovascular events and mortality as well as increased bleeding risk caused by the preventive antiplatelet treatment were modelled accordingly in our model. All the model parameters are shown in Table 1.

\section{Transition probabilities}

Transition probabilities for PAD patients were calculated from the REACH (Reduction of Athero-thrombosis for Continued Health) registry. This multinational database contains 68,375 consecutive outpatients from 5587 physician practices in 44 countries and was enrolled between December 2003 and June 2004 [24]. Patients on anti-platelet preventive treatment have reduced cardiovascular morbidity and mortality but on the other hand this treatment increases the risk of bleeding in the recipients. Transition probabilities for cardiovascular events in patients receiving Aspirin were calculated from a meta-analysis of randomised trials 'Aspirin for the Prevention of Cardiovascular Events in Patients With Peripheral Artery Disease' [26]. Probabilities for Clopidogrel were calculated from a Cochrane review of anti-platelet agents for intermittent claudication [28]. Bleeding risks in patients receiving low dose aspirin or clopidogrel were assigned from a randomized, blinded, trial of clopidogrel versus aspirin in patients at risk of ischemic events (CAPRIE) [27].

\section{Costs}

The acute phase costs and subsequent costs of cardiovascular events were taken from Thurston et al. [21] and the costs of amputation and of cardiovascular death are from Oostenbrink et al. [20]. The annual costs for an average PAD patient were published by van Asselt et al. [18] Dutch costs of anti-platelet medications aspirin and clopidogrel were obtained from the medicine cost website in the Netherlands [19]. Travel costs for attending the PAD screening were calculated based on the average distance to a primary practice. The average distance to a Dutch primary practice is $1.1 \mathrm{KM}$ [32]. Cost of a session at a primary care physician and productivity loss for a 55 years old individual in the Netherlands are published in the Dutch manual for costing in economic evaluations [33]. All costs used in the model were converted to Year 2012 Dutch costs using harmonized index of consumer prices data from the Dutch bureau of statistics [34].

\section{Utilities}

Since Dutch utility scores for the health states defined in our model were not found in the literature, we used
Sullivan et al. to estimate utilities for all the health states except amputation [30]. The utility of an amputee using standard gamble method was taken from Berry et al. [31].

\section{Analysis}

Discounted and undiscounted expected life years and QALYs (1.5\% discount rate), and costs (discount rate $4 \%$ ) for each strategy were calculated. Based on the discounted expected values, the Incremental Cost Effectiveness Ratios (ICERs) of the screening and treatment strategy were calculated over the standard existing practice of no screening and preventive treatment with low dose aspirin for incidentally diagnosed or symptomatic patients only.

The results of cost-effectiveness analysis were based on Probabilistic Sensitivity Analysis (PSA). Results of 1000 Monte Carlo simulations were graphically displayed in the form of cost-effectiveness planes (CE planes) and the subsequent probability of being cost-effective at different values of willingness to pay (WTP) thresholds was shown as cost-effectiveness acceptability curves (CEACs).

One way sensitivity analyses were performed to identify the two most influential model parameters affecting model outputs. For this purpose, upper and lower limits of $95 \%$ confidence interval of model parameters were used. Then, a two way sensitivity analysis was conducted for combinations of values tested for these two most influential parameters.

\section{Scenario analysis}

We performed a scenario analysis by replacing routinely prescribed low dose aspirin with a relatively new antiplatelet drug clopidogrel for the secondary prevention of cardiovascular events in identified PAD patients.

\section{Results}

\section{Cost-effectiveness analysis}

The expected model outcomes show that the targeted ABI screening and treatment with low dose aspirin produce 21.79 mean LYs and 15.66 mean QALYs for a cost of 26,548 Euros. The cost of PAD screening and treatment followed by low dose aspirin was 1503 Euros lower compared to 'no screening' and 0.07 QALYs were gained (Table 2). Therefore, ABI screening followed by preventive treatment with low dose aspirin is a dominant strategy. The relationship between costs and effects and the uncertainty surrounding these estimates are shown in the cost effectiveness planes in the Figure 3. Monte Carlo simulation shows that the $88 \%$ of ICER dots are in the right lower quadrant indicating that the strategy 'PAD screening' tended to have favourable health outcomes against lower costs in comparison with a strategy of 'no screening'. The probability of being cost effective at different values of willingness to pay (WTP) thresholds 
Table 1 Model parameters and distribution used in the probabilistic sensitivity analyses

\begin{tabular}{|c|c|c|c|c|}
\hline Model parameter & Value & Probability distribution & $\begin{array}{l}\text { Moments of the probability } \\
\text { distribution } \dot{\alpha} / \mathrm{min}, \beta / \max \end{array}$ & Source \\
\hline \multicolumn{5}{|l|}{ Discount rates } \\
\hline Cost discount rate & $4 \%$ & Fixed & - & {$[14]$} \\
\hline Outcome discount rate & $1.5 \%$ & Fixed & - & [14] \\
\hline \multicolumn{5}{|l|}{ Costs (Euros)* } \\
\hline Cost of ankle brachial index test & $74 \dagger$ & BETA Pert & $55.7 ; 92.8$ & MUMC \\
\hline Annual cost of PAD treatment & 2369 & GAMMA & $325.09 ; 7.29$ & [18] \\
\hline Annual cost of Aspirin & 10 & Fixed & & [19] \\
\hline Annual cost of Clopidogrel & 19 & Fixed & & [19] \\
\hline Costs of Amputation & $14343+$ & BETA Pert & $10683 ; 17804$ & [20] \\
\hline Cost of AMI in first year & 25328 & GAMMA & $100 ; 253.27$ & [21] \\
\hline Annual costs of MI treatment in subsequent years & 3584 & GAMMA & $99.92 ; 35.86$ & [21] \\
\hline Cost of stroke in first year & 27964 & GAMMA & $99.99 ; 279.66$ & [21] \\
\hline Annual costs of treatment of stroke in subsequent years & 10646 & GAMMA & $99.99 ; 106.47$ & [21] \\
\hline Costs of bleeding & 3457 & GAMMA & $99.87 ; 34.61$ & {$[21]$} \\
\hline \multicolumn{5}{|l|}{ ABI test accuracy } \\
\hline Sensitivity & $0.90+$ & BETA Pert & $0.68 ; 1$ & [22] \\
\hline Specificity & $0.95+$ & BETA Pert & $0.71 ; 1$ & {$[22]$} \\
\hline \multicolumn{5}{|l|}{ Incidence/prevalence of PAD } \\
\hline Prevalence of PAD & 0.184 & BETA & $1372 ; 6082$ & [6] \\
\hline Annual incidence of PAD in 55-64 years aged & 0.005 & BETA & See Additional file 1 & [23] \\
\hline Annual incidence of PAD in 65-74 years aged & 0.007 & BETA & See Additional file 1 & {$[23]$} \\
\hline Annual incidence of PAD in $75-84$ years aged & 0.008 & BETA & See Additional file 1 & [23] \\
\hline Annual incidence of PAD in $>85$ years aged & 0.010 & BETA & See Additional file 1 & {$[23]$} \\
\hline \multicolumn{5}{|l|}{ Event probabilities } \\
\hline Probability of amputation in patients with no PAD & 0.003 & BETA & $32 ; 11734$ & {$[24]$} \\
\hline Probability of AMI in patients with no PAD & 0.008 & BETA & $89 ; 11677$ & {$[24]$} \\
\hline Probability of stroke in patients with no PAD & 0.008 & BETA & $94 ; 11672$ & [24] \\
\hline Probability of amputation in PAD patients & 0.016 & BETA & $140 ; 8441$ & {$[24]$} \\
\hline Probability of AMI in PAD patients & 0.013 & BETA & $111 ; 8470$ & {$[24]$} \\
\hline Probability of stroke in PAD patients & 0.019 & BETA & $165 ; 8416$ & [24] \\
\hline Probability of symptomatic PAD & 0.3 & BETA & $138 ; 320$ & {$[25]$} \\
\hline Relative risk in PAD patients on low dose aspirin & 0.78 & BETA & $25.45 ; 7.2$ & [26] \\
\hline Probability of bleeding in PAD patients on aspirin & 0.026 & BETA & $255 ; 9311$ & [27] \\
\hline Relative risk in PAD patients on Clopidogrel & 0.616 & BETA & See Additional file 1 & {$[28]$} \\
\hline Probability of bleeding in PAD patients on Clopidogrel & 0.020 & BETA & $191 ; 9386$ & {$[27]$} \\
\hline \multicolumn{5}{|l|}{ Mortality in 'untreated' patients } \\
\hline Annual probability of death in PAD patients & 0.037 & BETA & $323 ; 8258$ & {$[24]$} \\
\hline Probability of death in post Amputation & 0.155 & BETA & $4297 ; 21281$ & {$[29]$} \\
\hline annual probability of death in post $\mathrm{Ml}$ alive patients & 0.028 & BETA & $521 ; 17492$ & {$[24]$} \\
\hline annual probability of death in post stroke alive patients & 0.031 & BETA & $1212 ; 37390$ & [24] \\
\hline \multicolumn{5}{|l|}{ Utility } \\
\hline PAD & 0.652 & BETA & $0.8 ; 0.4$ & {$[30]$} \\
\hline Amputation & 0.45 & BETA & $210.8 ; 257.7$ & {$[31]$} \\
\hline
\end{tabular}


Table 1 Model parameters and distribution used in the probabilistic sensitivity analyses (Continued)

\begin{tabular}{lllll}
\hline Post Ml & 0.671 & BETA & $69.3 ; 34$ & [30] \\
Post stroke & 0.519 & BETA & $2.7 ; 2.5$ & [30] \\
Post bleed & 0.627 & BETA & $405.6 ; 241.13$ & {$[30]$} \\
\hline
\end{tabular}

*All costs were converted to 2012 Dutch costs using harmonized index of consumer prices (HICP).

¥This cost was obtained from the Financial department of Maastricht University Medical Centre.

†Mode for BETA Pert distribution.

was shown as cost effectiveness acceptability curves (CEACs) in the Figure 4. The curves show the probability of PAD screening being cost effective at a range of Willingness To Pay thresholds. There is $88 \%$ probability of PAD screening being cost effective at the WTP of 40000 Euros.

Scenario analysis with the use of clopidogrel as an alternative anti-platelet therapy produced similar results indicating dominance over 'no screening' (Table 2).

The one way sensitivity analysis identified PAD prevalence and relative risk reduction by low dose aspirin in the treated PAD patients, as the two most influential model parameters. Although the ICER for ABI screening remained dominant for all the variations in parameter values, two way sensitivity analysis varying PAD prevalence and relative risk reduction by aspirin showed a consistent QALY gain by either increasing the prevalence of PAD or relative risk reduction by low dose aspirin.

\section{Discussion}

Our cost-effectiveness model output suggests that targeted screening of high risk individuals and consequent secondary prevention of cardiovascular events by anti-platelet medication is cost effective and results in significant health gain by reducing cardiovascular events in PAD patients.
The analysis has been performed from societal perspective and all direct and indirect costs are incorporated for all the health states in the model. Our analysis interprets that PAD screening and anti-platelet preventive treatment is a highly cost-effective intervention. Changing the analysis perspective to health care payer's, would further strengthen this interpretation. This is the case in countries like the United Kingdom where health care is financed by general taxation, a health care provider's (National Health Services) perspective is used in pharmaco-economic analyses and only direct costs are covered.

A recent meta-analysis concluded that measurement of the ankle brachial index may improve the accuracy of cardiovascular risk prediction beyond the Framingham Risk Score [35]. After adjustment for the Framingham risk score, the ABI provided significant improvement in predicting cardiovascular risk independent of established risk factors in a broad population. There is unequivocal evidence establishing the importance of targeted $\mathrm{ABI}$ screening [36,37].

In our model costs and effects were modeled for aspirin and clopidogrel. The CAPRIE trial data show that clopidogrel is more effective than aspirin in reducing cardiovascular events in the subgroup of patients with

Table 2 Results - base case analysis and scenario analysis

\begin{tabular}{|c|c|c|c|c|c|c|c|c|}
\hline \multicolumn{9}{|c|}{ PROBABILISTIC RESULTS (discounted) } \\
\hline Diagnostic test & Treatment & Costs & LYs & QALYs & iCosts & iLY & iQALYs & iCERs \\
\hline \multicolumn{9}{|l|}{ Base case } \\
\hline No screen & Low dose aspirin & 28052 & 20.69 & 15.58 & & & & \\
\hline $\mathrm{ABI}$ screening & Low dose aspirin & 26548 & 21.79 & 15.66 & -1503 & 1.10 & 0.007 & Dominant \\
\hline \multicolumn{9}{|c|}{ Scenario analysis with Clopidogrel } \\
\hline No screen & Clopidogrel & 29464 & 22.33 & 15.95 & & & & \\
\hline$A B \mid$ & Clopidogrel & 27681 & 22.57 & 16.17 & -1783 & 0.24 & 0.22 & Dominant \\
\hline \multicolumn{9}{|c|}{ PROBABILISTIC RESULTS (undiscounted) } \\
\hline Diagnostic test & Treatment & Costs & LYs & QALYs & iCosts & iLY & iQALYs & \\
\hline \multicolumn{9}{|l|}{ Base case } \\
\hline No screen & Low dose aspirin & 63155 & 26.32 & 19.40 & & & & \\
\hline $\mathrm{ABI}$ screening & Low dose aspirin & 59544 & 27.47 & 19.50 & -3611 & 1.15 & 0.11 & \\
\hline \multicolumn{9}{|c|}{ Scenario analysis with Clopidogrel } \\
\hline No screen & Clopidogrel & 67799 & 28.30 & 19.96 & & & & \\
\hline$A B \mid$ & Clopidogrel & 63759 & 28.66 & 20.27 & -4039 & 0.36 & 0.31 & \\
\hline
\end{tabular}




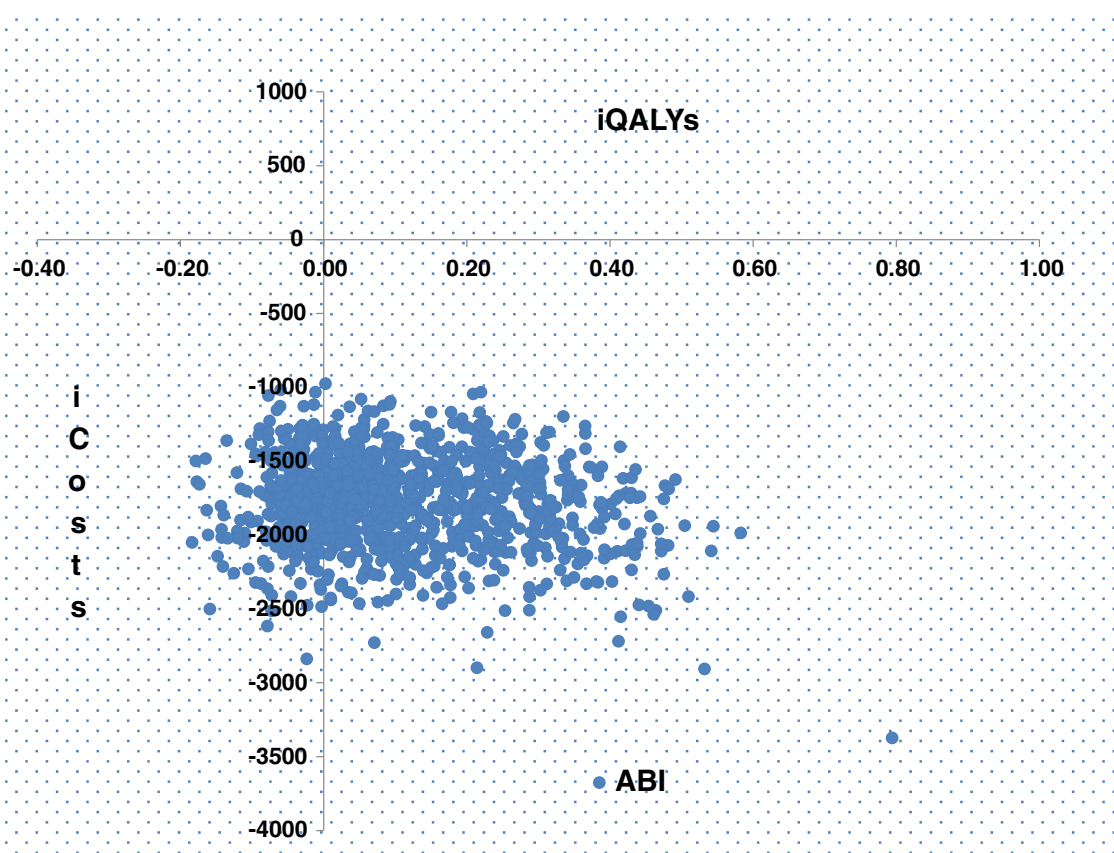

Figure 3 incremental Cost-effectiveness planes. Shows that PAD screening followed by low dose aspirin treatment was a dominant strategy (less costly, more effective) in $88 \%$ of simulations.

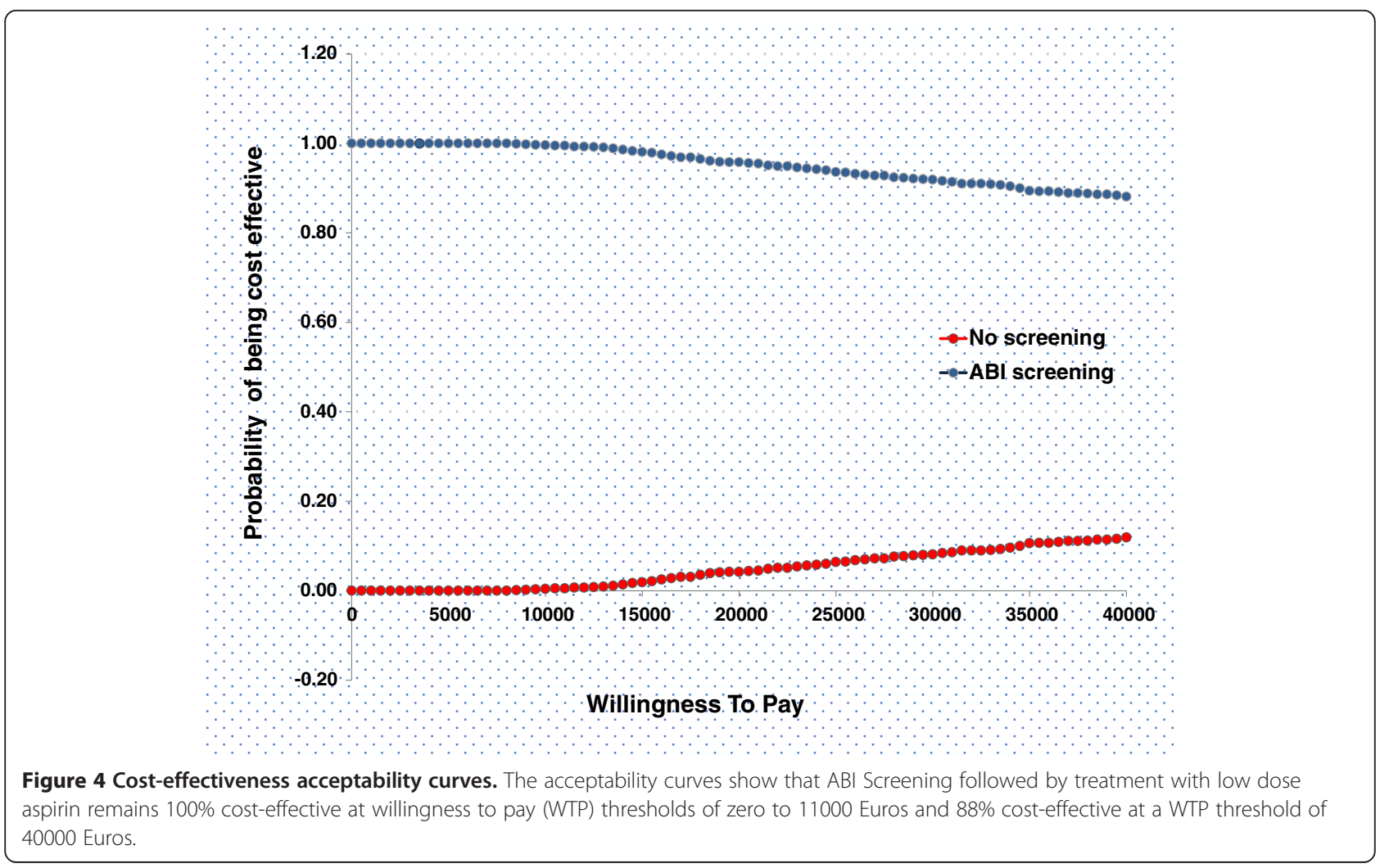


PAD [27]. However, with branded clopidogrel (Plavix), cost was a major barrier for longer-term use. Plavix (clopidogrel) lost its patent protection from May 2012 and the generic form of clopidogrel is available at a much lower cost. Since branded Plavix may have been cost-prohibitive in certain non-reimbursement settings, there will likely be an increase in compliance with long-term generic clopidogrel therapy. Economic model results for the use of clopidogrel in PAD patients were in line with previous studies establishing the cost-effectiveness of this drug $[38,39]$. These results were expected as generic clopidogrel costs only few Euros more than aspirin and provides higher risk reduction from $\mathrm{C}$ The limitation of our model is that the costs and health outcomes of only antiplatelet treatment are modeled. Depending upon the identified risk factors in the individual patients many additional medication interventions such as statins and tension lowering medications are prescribed for the medical management of PAD. However, our study focusses on antiplatelet treatment using Aspirin or Clopidogrel as this is the most commonly prescribed medication in almost all the patients. In order to model the additional therapies for each subgroup of high risk patients a much more complex model is needed.

ABI has been in wide use at specialized vascular clinics but its application in primary practice is limited. With a high degree of diagnostic accuracy and as much prognostic information, ABI screening is a cost-effective but underused primary care tool to detect PAD. Mohler et al. found that the time to perform ABI, staff constrains and lack of reimbursement are the most important barriers in its use and appropriate measures are required to deal with these barriers [40]. However, this cost-effective analysis clearly indicates that the ABI screening is a highly cost-effective clinical tool to be applied in the primary care.

In the real world scenario, compliance to the $\mathrm{ABI}$ screening and to the preventive treatment thereafter, in an apparently healthy population could pose a challenge. However, factors like the noninvasive nature of the $\mathrm{ABI}$ testing and routine primary care visits of high risk individuals are likely to contribute to good compliance. Although lower compliance to the screening programme may affect the overall cost effectiveness results, it is unlikely to negate the cost-effectiveness of ABI screening altogether because of the high probability of the screening programme to be cost-effective as shown in the cost-effectiveness plane (Figure 4).

Our results are in line with a previously published modeling study by Sigvant et al. to assess the costeffectiveness of various therapeutic agents in asymptomatic PAD patients. Aspirin as one of the preventive therapies produced similar health outcomes in 55 yearold patients as our model [41].
In line with ACC/AHA guidelines, this modeling study is only based upon risk reduction by preventive antiplatelet therapy given to the PAD patients. Additional cardiovascular risk reducing treatments such as exercise therapy, lipid lowering statins and blood pressure lowering drugs are also prescribed in PAD. Further research is required to quantify the consolidated effects of diverse preventive options in a heterogenic PAD population.

\section{Conclusions}

This study has assessed the impact of PAD screening using long term clinical and economic outcomes. The results show that targeted ABI screening and consequent secondary prevention of cardiovascular events using low dose aspirin or clopidogrel is a cost-effective strategy. Our study results provide one of the building blocks of evidence expansion for advocating PAD screening and the promotion of its more widespread use to detect and treat PAD patients. Implementation of targeted PAD screening and subsequent treatment in primary care practices and in public health programs is likely to improve the societal health and to save health care costs by reducing catastrophic cardiovascular events.

\section{Additional file}

Additional file 1: Calculation of probabilistic moments for PAD Incidence.

\section{Abbreviations}

PAD: Peripheral arterial disease; ABI: Ankle brachial index; WTP: Willingness to pay; QoL: Quality of life; ESC: European Society of Cardiology; AHA: American Heart Association; ACC: American College of Cardiology; USPSTF: United States Preventive Services Task Force; EBM: Evidence Based Medicine; REACH: Reduction of athero-thrombosis for continued health; CAPRIE: Clopidogrel versus aspirin in patients at risk of ischemic events; CE planes: Cost effectiveness planes; LY: Life years; QALY: Quality-adjusted life year; ICER: Incremental cost effectiveness ratio; CEAC: Cost-effectiveness acceptability curve.

\section{Competing interests}

None of the authors have any competing interests.

\section{Authors' contributions}

AV and MJ: Conceived the study, assimilated all necessary data for PAD, performed the cost-effectiveness analysis, interpreted the results and drafted the manuscript. AT and HT: Supplied all data required from the academic hospital and helped to draft the manuscript. JS: Gave advice on all statistical analyses performed, instructed on the study methodology and reviewed the manuscript multiple times. All authors read and approved the final manuscript.

\section{Acknowledgments}

This research was performed within the framework of CTMM, the Centre for Translational Molecular Medicine (http://www.ctmm.nl), project INCOAG (grant 01C-201), and supported by the Dutch Heart Foundation.

\section{Author details}

${ }^{1}$ Department of Clinical Epidemiology and Medical Technology Assessment (KEMTA), Maastricht University Medical Centre, Maastricht, The Netherlands. ${ }^{2}$ School for Public Health and Primary Care (CAPHRI), Maastricht University, Maastricht, The Netherlands. ${ }^{3}$ Laboratory for Clinical Thrombosis and 
Haemostasis, Department of Internal Medicine, Cardiovascular Research Institute Maastricht (CARIM), Maastricht University Medical Centre, Maastricht, the Netherlands. ${ }^{4}$ Institute of Health Policy \& Management, Erasmus University Rotterdam, Rotterdam, the Netherlands.

Received: 31 October 2013 Accepted: 23 January 2014

Published: 29 January 2014

\section{References}

1. Hirsch AT, Criqui MH, Treat-Jacobson D, Regensteiner JG, Creager MA, Olin JW, Krook SH, Hunninghake DB, Comerota AJ, Walsh ME, et al: Peripheral arterial disease detection, awareness, and treatment in primary care. Jama 2001, 286(11):1317-1324.

2. Belch JJ, Topol EJ, Agnelli G, Bertrand M, Califf RM, Clement DL, Creager MA, Easton JD, Gavin JR 3rd, Greenland P, et al: Critical issues in peripheral arterial disease detection and management: a call to action. Arch Intern Med 2003, 163(8):884-892.

3. Criqui $\mathrm{MH}$, Denenberg JO: The generalized nature of atherosclerosis: how peripheral arterial disease may predict adverse events from coronary artery disease. Vasc Med 1998, 3(3):241-245

4. McDermott MM, Liu K, Greenland P, Guralnik JM, Criqui MH, Chan C, Pearce WH, Schneider JR, Ferrucci $\mathrm{L}$, Celic $\mathrm{L}$, et al: Functional decline in peripheral arterial disease: associations with the ankle brachial index and leg symptoms. Jama 2004, 292(4):453-461.

5. Criqui MH, Langer RD, Fronek A, Feigelson HS, Klauber MR, McCann TJ, Browner D: Mortality over a period of 10 years in patients with peripheral arterial disease. N Engl J Med 1992, 326(6):381-386.

6. Bendermacher BLW, Teijink JAW, Willigendael EM, Bartelink M-L, Peters RJG, de Bie RA, Büller HR, Boiten J, Langenberg M, Prins MH: A clinical prediction model for the presence of peripheral arterial disease - the benefit of screening individuals before initiation of measurement of the anklebrachial index: an observational study. Vasc Med 2007, 12(1):5-11.

7. Tendera M, Aboyans V, Bartelink ML, Baumgartner I, Clement D, Collet JP Cremonesi A, De Carlo M, Erbel R, Fowkes FG, et al: ESC Guidelines on the diagnosis and treatment of peripheral artery diseases: Document covering atherosclerotic disease of extracranial carotid and vertebral, mesenteric, renal, upper and lower extremity arteries: the Task Force on the Diagnosis and Treatment of Peripheral Artery Diseases of the European Society of Cardiology (ESC). Eur Heart J 2011, 32(22):2851-2906.

8. Hirsch AT, Haskal ZJ, Hertzer NR, Bakal CW, Creager MA, Halperin JL, Hiratzka LF, Murphy WR, Olin JW, Puschett JB, et al: ACC/AHA 2005 guidelines for the management of patients with peripheral arterial disease (lower extremity, renal, mesenteric, and abdominal aortic): executive summary a collaborative report from the American Association for Vascular Surgery/Society for Vascular Surgery, Society for Cardiovascular Angiography and Interventions, Society for Vascular Medicine and Biology, Society of Interventional Radiology, and the ACC/AHA Task Force on Practice Guidelines (Writing Committee to Develop Guidelines for the Management of Patients With Peripheral Arterial Disease) endorsed by the American Association of Cardiovascular and Pulmonary Rehabilitation; National Heart, Lung, and Blood Institute; Society for Vascular Nursing; TransAtlantic Inter-Society Consensus; and Vascular Disease Foundation. J Am Coll Cardiol 2006, 47(6):1239-1312.

9. United States Preventive Services Task Force: Recommendation Statement: Screening for Peripheral Arterial Disease. Washington, DC: Agency for Healthcare Research and Quality; 2005:1-8.

10. Beckman JA, Jaff MR, Creager MA: The United States preventive services task force recommendation statement on screening for peripheral arterial disease: more harm than benefit? Circulation 2006, 114(8):861-866.

11. Perlstein TS, Creager MA: The ankle-brachial index as a biomarker of cardiovascular risk: it's not just about the legs. Circulation 2009, 120(21):2033-2035

12. Rooke TW, Hirsch AT, Misra S, et al: 2011 ACCF/AHA Focused Update of the Guideline for the Management of Patients With Peripheral Artery Disease (Updating the 2005 Guideline)A Report of the American College of Cardiology Foundation/American Heart Association Task Force on Practice Guidelines. J Am Coll Cardio/ 2011, 58(19):2020-2045.

13. Meijer WT, Grobbee DE, Hunink MG, Hofman A, Hoes AW: Determinants of peripheral arterial disease in the elderly: the Rotterdam study. Arch Intern Med 2000, 160(19):2934-2938.
14. Guidelines for pharmacoeconomic research, updated version. Diemen: College voor zorgverzekeringen; 2006. available from http://www.ispor.org/peguidelines/ source/HTAGuidelinesNLupdated2006.pdf accessed on 15 Nov 2011.

15. Dekker JM, Alssema M, Janssen PG, Goudswaard LN: [Summary of the practice guideline 'The Prevention Visit' from the Dutch College of General Practitioners]. Nederlands tijdschrift voor geneeskunde 2011, 155(18):A3428

16. Vaidya A, Joore MA, Ten Cate-Hoek AJ, Kleinegris MC, Ten Cate H, Severens JL A systematic review of model-based economic evaluations of diagnostic and therapeutic strategies for lower extremity artery disease. Thromb Haemost 2014, 111(1):19-28

17. Sonnenberg FA, Beck JR: Markov models in medical decision making: a practical guide. Med Decis Making 1993, 13(4):322-338.

18. van Asselt ADI, Nicolaï SPA, Joore MA, Prins MH, Teijink JAW: Costeffectiveness of Exercise Therapy in Patients with Intermittent Claudication: supervised exercise therapy versus a 'Go Home and Walk' Advice. Eur J Vasc Endovasc Surg 2011, 41(1):97-103.

19. The Dutch website for the costs of the medicines which gives consumer reimbursement prices. available at http://www.medicijnkosten.nl/ accessed on 12 Jan 2013.

20. Oostenbrink JB, Tangelder MJ, Busschbach JJ, van Hout BA, Buskens E, Algra A, Lawson JA, Eikelboom BC: Cost-effectiveness of oral anticoagulants versus aspirin in patients after infrainguinal bypass grafting surgery. J Vasc Surg 2001, 34(2):254-262.

21. Thurston SJ, Heeg B, de Charro F, van Hout B: Cost-effectiveness of clopidogrel in STEMI patients in the Netherlands: a model based on the CLARITY trial. Curr Med Res Opin 2010, 26(3):641-651.

22. Lijmer JG, Hunink MG, van den Dungen JJ, Loonstra J, Smit AJ: ROC analysis of noninvasive tests for peripheral arterial disease. Ultrasound Med Biol 1996, 22(4):391-398.

23. Meijer WT, Cost B, Bernsen RM, Hoes AW: Incidence and management of intermittent claudication in primary care in The Netherlands. Scand J Prim Health Care 2002, 20(1):33-34.

24. Steg PG, Bhatt DL, Wilson PW, D'Agostino R Sr, Ohman EM, Rother J, Liau CS, Hirsch AT, Mas JL, Ikeda Y, et al: One-year cardiovascular event rates in outpatients with atherothrombosis. Jama 2007, 297(11):1197-1206.

25. Hooi JD, Kester AD, Stoffers HE, Rinkens PE, Knottnerus JA, van Ree JW Asymptomatic peripheral arterial occlusive disease predicted cardiovascular morbidity and mortality in a 7-year follow-up study. J Clin Epidemiol 2004, 57(3):294-300.

26. Berger JS, Krantz MJ, Kittelson JM, Hiatt WR: Aspirin for the prevention of cardiovascular events in patients with peripheral artery disease: a meta-analysis of randomized trials. Jama 2009, 301(18):1909-1919.

27. A randomised, blinded, trial of clopidogrel versus aspirin in patients at risk of ischaemic events (CAPRIE). Lancet 1996, 348(9038):1329-1339.

28. Wong PF, Chong LY, Mikhailidis DP, Robless P, Stansby G: Antiplatelet agents for intermittent claudication. Cochrane Database Syst Rev 2011, 11:CD001272

29. Moxey PW, Hofman D, Hinchliffe RJ, Jones K, Thompson MM, Holt PJ: Epidemiological study of lower limb amputation in England between 2003 and 2008. Br J Surg 2010, 97(9):1348-1353.

30. Sullivan PW, Slejko JF, Sculpher MJ, Ghushchyan V: Catalogue of EQ-5D Scores for the United Kingdom. Med Decis Mak 2011, 31(6):800-804.

31. Berry E, Kelly S, Westwood ME, Davies LM, Gough MJ, Bamford JM, Meaney JF, Airey CM, Cullingworth J, Barbieri $M$, et al: The cost-effectiveness of magnetic resonance angiography for carotid artery stenosis and peripheral vascular disease: a systematic review. Health Technol Assess 2002, 6(7):1-155.

32. Hakkaart-van Roijen LTS, Bouwmans CAM: Handleiding voor kostenonderzoek, methoden en standaard kostprijzen voor economische evaluaties in de gezondheidszorg. College voor zorgverzekeringen. Geactualiseerde versie 2010. [Manual for cost analysis in health care; Dutch]. Rotterdam, the Netherlands; 2011:2010.

33. Tan SS, Bouwmans CA, Rutten FF, Hakkaart-van Roijen L: Update of the dutch manual for costing in economic evaluations. Int $J$ Technol Assess Health Care 2012, 28(2):152-158.

34. Consumer prices; European harmonised price index. http://statline.cbs.nl/ StatWeb/publication/?DM $=$ SLEN\&PA $=80087$ ENG\&D1 $=0 \& D 2=0 \& D 3=38,51,64$, $77,90,103,1 \& L A=E N \& H D R=G 1, T \& S T B=G 2 \& W=T$ accessed on 12 Jan 2012.

35. Ankle Brachial Index C, Fowkes FG, Murray GD, Butcher I, Heald CL, Lee RJ, Chambless LE, Folsom AR, Hirsch AT, Dramaix M, et al: Ankle brachial index 
combined with Framingham Risk Score to predict cardiovascular events and mortality: a meta-analysis. Jama 2008, 300(2):197-208.

36. Bendermacher BL, Teijink JA, Willigendael EM, Bartelink ML, Peters RJ, Langenberg M, Buller HR, Prins MH: Applicability of the ankle-brachialindex measurement as screening device for high cardiovascular risk: an observational study. BMC cardiovascular disorders 2012, 12:59.

37. Fowkes FG, Rudan D, Rudan I, Aboyans V, Denenberg JO, McDermott MM, Norman PE, Sampson UK, Williams LJ, Mensah GA, et al: Comparison of global estimates of prevalence and risk factors for peripheral artery disease in 2000 and 2010: a systematic review and analysis. Lancet 2013, 382(9901):1329-1340.

38. Schleinitz MD, Weiss JP, Owens DK: Clopidogrel versus aspirin for secondary prophylaxis of vascular events: a cost-effectiveness analysis. Am J Med 2004, 116(12):797-806.

39. Karnon J, Brennan A, Pandor A, Fowkes G, Lee A, Gray D, Coshall C, Nicholls C, Akehurst $R$ : Modelling the long term cost effectiveness of clopidogrel for the secondary prevention of occlusive vascular events in the UK. Curr Med Res Opin 2005, 21(1):101-112.

40. Mohler ER, Treat-Jacobson D, Reilly MP, Cunningham KE, Miani M, Criqui MH, Hiatt WR, Hirsch AT: Utility and barriers to performance of the ankle brachial index in primary care practice. Vasc Med 2004, 9(4):253-260.

41. Sigvant B, Henriksson M, Lundin F, Wahlberg E: Asymptomatic peripheral arterial disease: is pharmacological prevention of cardiovascular risk cost-effective? Eur J Cardiovasc Prev Rehabil 2011, 18(2):254-261.

doi:10.1186/1471-2458-14-89

Cite this article as: Vaidya et al:: Screen or not to screen for peripheral arterial disease: guidance from a decision model. BMC Public Health 2014 14:89.

\section{Submit your next manuscript to BioMed Central and take full advantage of:}

- Convenient online submission

- Thorough peer review

- No space constraints or color figure charges

- Immediate publication on acceptance

- Inclusion in PubMed, CAS, Scopus and Google Scholar

- Research which is freely available for redistribution 